\title{
QUANTIFICATION OF ANTICOAGULANTS DABIGATRAN, RIVAROXABAN, AND PRASUGREL BY CHROMATOGRAPHIC AND SPECTROMETRIC TECHNIQUES - REVIEW
}

\author{
SATYA PRASAD B, JAYAKUMARI $\mathbf{S}^{*}$
}

Department of Pharmacognosy, School of Pharmaceutical Sciences, Vistas, Chennai, Tamil Nadu, India. Email: nisajayaa@gmail.com

Received: 16 October 2018, Revised and Accepted: 26 February 2019

ABSTRACT

A review is presented on different analytical techniques used for quantitative analysis of selected anticoagulants dabigatran, rivaroxaban, and prasugrel. Efforts have been made to collate all the relevant references to the extent possible. The review discusses the advantages and disadvantages of the cited analytical techniques, which will help to give insights into the methods used for estimation of selected anticoagulants such as dabigatran, rivaroxaban, and prasugrel, from clinical isolates, and its dosage forms. The review highlights the basic as well as advanced techniques performed for estimating dabigatran, rivaroxaban, and prasugrel. The techniques illustrated here have been demonstrated to be useful for quantitative determination of selected anticoagulants and may find application in analyzing other related properties.

Keywords: Rivaroxaban, Dabigatran, Quantification, Prasugrel, Analyte.

(c) 2019 The Authors. Published by Innovare Academic Sciences Pvt Ltd. This is an open access article under the CC BY license (http://creativecommons. org/licenses/by/4. 0/) DOI: http://dx.doi.org/10.22159/ajpcr.2019.v12i4.29954

\section{INTRODUCTION}

A blood clot is a clump of blood that has changed from a liquid to a gellike or semisolid state. Clotting or coagulation is a necessary process that can prevent you from losing too much blood in certain instances, such as when you're injured or cut. When a clot forms inside one of your veins, it won't always dissolve on its own. This can be a very dangerous and even life-threatening situation. There are many types of blood coagulation deep vein thrombosis, pulmonary embolism, coronary embolism, and cerebral embolism. Hence, blood thinners are used (Anticoagulant), it is necessary to treat and prevent various blood clot in vivo condition.

In current scenario, numerous intravenous and oral anticoagulants are used for treatment of in vivo blood coagulation. Those are Indirect thrombin inhibitors-Heparin derivatives Fondaparinux, danaparoid, enoxaparin and dalteparin, Direct thrombin inhibitors- Lepirudin, Bivaluridin, Hirudin or Leechin and Oral ones- Coumarin derivativesNicoumalone, Warfarin, Indanedione derivatives- Phenindione and Diphendione, Director factor-Xa inhibitors-Apixaban, Rivaroxaban, Edoxaban, Platelet aggregator inhibitor-Clopidogrel, Prasugrel and Oral direct thrombin inhibitors-Dabigatran etexilate etc. [1].

Dabigatran is rapid-acting competitive and reversible direct inhibitor of thrombin. It is chemically as $\mathrm{N}-[2-[4-[\mathrm{N}-(\mathrm{Hexyloxycarbonyl)}$ amidino] phenylaminomethyl]-1-methyl-1H-benzimidazol-5-ylcarbonyl]-N(2-pyridyl)-beta-alanine ethyl ester (Fig. 1). It is a light yellow to dark yellow solid with the empirical formula $\mathrm{C}_{34} \mathrm{H}_{41} \mathrm{~N}_{7} \mathrm{O}_{5}$ and molar mass of $627.746 \mathrm{~g} / \mathrm{mol}$.

Rivaroxaban chemically described as 5-chloro-N-[[(5S)-2-oxo-3-[4-(3oxomorpholin-4-yl) phenyl]-1, 3-oxazolidin-5-yl] methyl] thiophene2-carboxamide (Fig. 2), it is a highly selective direct Factor Xa inhibitor. It is an empirical formula $\mathrm{C}_{19} \mathrm{H}_{18} \mathrm{ClN}_{3} \mathrm{O}_{5} \mathrm{~S}$ and molecular weight of $435.882 \mathrm{~g} / \mathrm{mol}$.

Prasugrel chemically prasugrel chemically is 5-[2-cyclopropyl -1(2- fluorophenyl)-2-oxoethyl]-4, 5, 6, 7-tetra hydro thieno [3, 2-c] pyridin-2-yl acetate (Fig. 3), it reduces the aggregation ("clumping") of platelets by irreversibly binding to P2Y12 receptors. It is empirical formula $\mathrm{C}_{20} \mathrm{H}_{20} \mathrm{FNO}_{3} \mathrm{~S}$ and molecular weight of $435.882 \mathrm{~g} / \mathrm{mol}$.

In this article, we reviewed some analytical methods for the estimation of dabigatran, rivaroxaban, and prasugrel in pure drug and dosage forms.

\section{QUANTITATIVE ANALYTICAL TECHNIQUES FOR SELECTED ANTICOAGULANTS}

Analytical techniques for quantitative analysis help an analyst to accurately determine the concentration of an individual component in the test sample. The separation of the analyte is often performed before analysis by classical methods or during analysis by instrumental methods. Wet analytical methods such as titrations, precipitations, and extractions are used to estimate a drug or an analyte.

Instrumental methods for quantification of analyte use chromatography, electrophoresis, etc., for separation and physical properties such as absorption, fluorescence, conductivity, and light scattering are utilized to measure the analyte accurately and precisely.

The selected anticoagulants - dabigatran, rivaroxaban, and prasugrel can be estimated quantitatively using different methodologies. There are innumerable publications based on this simple basic technique, but a few were selected here.

Quantitative determination of dabigatran, rivaroxaban, and prasugrel

Spectroscopy

It is impossible to envision any literature reference not taking advantage of this powerful technique in assaying dabigatran. Many studies have focused on this technique and have performed quantitative estimation of dabigatran as an active pharmaceutical ingredient or in its dosage form, either when formulated alone or with other active components.

Spectrophotometric method used for the analysis of tablets of dabigatran was cited by Jayavarapu et al. [2]. The method used $0.1 \mathrm{~N}$ hydrochloric acid as the solvent due to stability in $\mathrm{HCl}$. The samples were scanned and analyzed at $326 \mathrm{~nm}$ wavelength. The method was found to be accurate, precise, and linear over the concentration ranges of $3-2 \mu \mathrm{g} / \mathrm{mL}$. Similarly, Prajapati et al.[3] published spectrophotometric method for estimation of dabigatran etexilate in bulk and its pharmaceutical dosage form. Dabigatran etexilate was estimated at $313 \mathrm{~nm}$. The linearity concentration ranges from 3 to $15 \mu \mathrm{g} / \mathrm{mL}$. The method was carried out zero-order spectrophotometric method applied successfully for the analysis of the drug in the pure and pharmaceutical dosage form. Hepsebah et al. [4] developed 


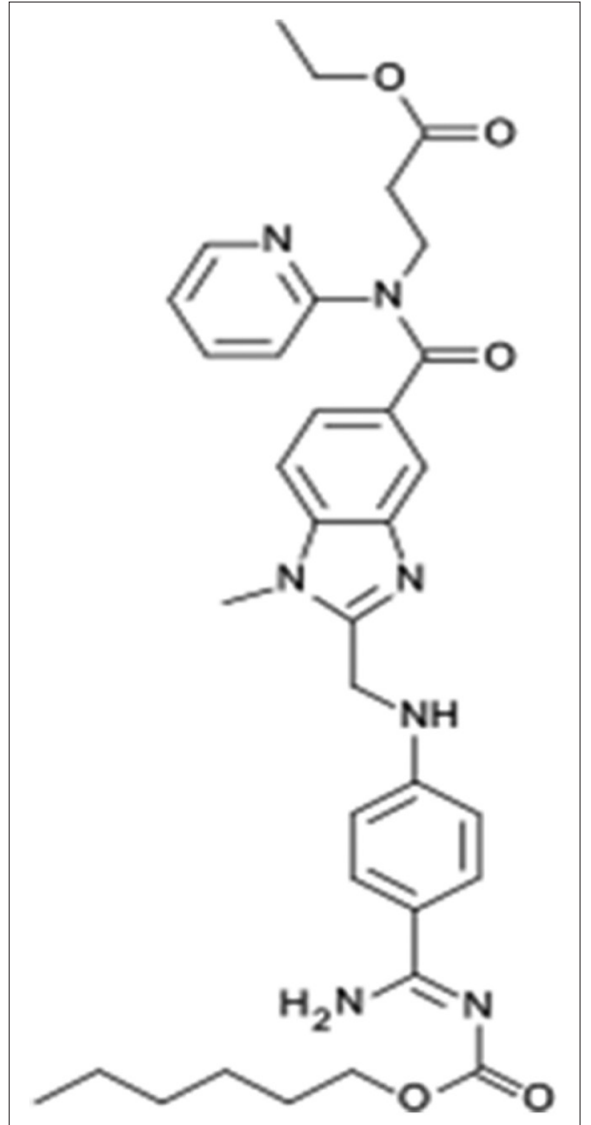

Fig. 1: Molecular structure of dabigatran

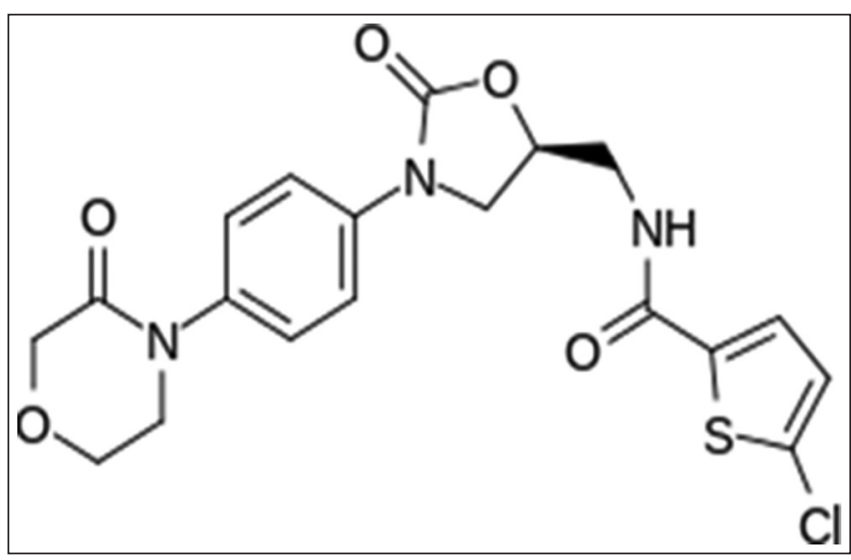

Fig. 2: Molecular structure of rivaroxaban

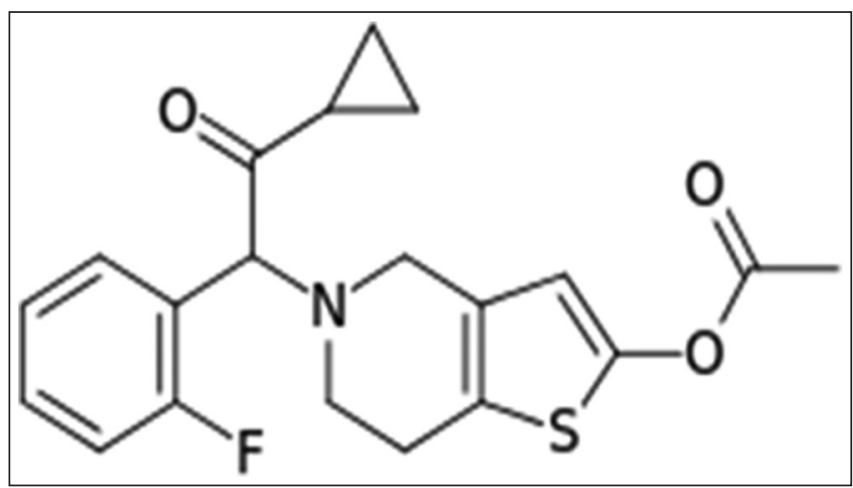

Fig. 3: Molecular structure of prasugre spectrometric dissolution method for dabigatran etexilate mesylate capsules, using $0.01 \mathrm{~N} \mathrm{HCl}$ as dissolution media, apparatus as USP Type 1 Basket, rpm as 100 , dissolution media temperature as $37 \pm 0.5^{\circ} \mathrm{C}$, dissolution volume as $500 \mathrm{ml}$, dissolution time point as $30 \mathrm{mts}$, and detection wavelength at $325 \mathrm{~nm}$. The developed method resulted in dabigatran etexilate exhibiting linearity in the range $1.25-10 \mu \mathrm{g} / \mathrm{ml}$. Harini et al. [5] developed and validated a simple, accurate, precise, and cost-effective UV-Spectrophotometric method for the estimation of dabigatran etexilate mesylate, the method was performed at $226 \mathrm{~nm}$ and the samples were prepared with methanol as solvent. Linearity range was found at $2-10 \mu \mathrm{g} / \mathrm{ml}$ in UV with a correlation coefficient (R) 0.999 . The proposed method was simple, precise, and accurate and can be used for the analysis of drug in bulk form. El-Din et al. [6] developed three rapid, accurate, and very simple derivative spectrophotometric methods for rivaroxaban and clopidogrel assay in their binary mixture and tablet dosage forms. First derivative spectrophotometric method, derivative amplitudes were measured at the zero crossing wavelength of 289 and $249.5 \mathrm{~nm}$ for estimation of rivaroxaban and clopidogrel, respectively. The linearity is over the range of $2.0-20.0 \mu \mathrm{g} / \mathrm{ml}$ for rivaroxaban and $5.0-60.0 \mu \mathrm{g} / \mathrm{ml}$ for clopidogrel. Seshamamba and Sekaran [7] described two simple spectrophotometric methods (I and II) for the determination of rivaroxaban in bulk and tablets. The method I is based on the reaction of rivaroxaban with 4-Chloro-7nitrobenzo-2-oxa-1, 3-diazole in alkaline medium. Method II involved the reaction of rivaroxaban with p-Dimethylamino cinnamaldehyde in acidic medium. The reactions products were measured at $405 \mathrm{~nm}$ and $545 \mathrm{~nm}$ for methods I and II, respectively. Sekaran et al. [8] developed UV-spectrophotometric method for the quantification of rivaroxaban in bulk. Rivaroxaban was estimated at $270 \mathrm{~nm}$ in dimethyl sulfoxide. The linearity range was found to be $2-20 \mu \mathrm{gL}^{-1}$. Sreeja et al. [9] developed two simple, sensitive, and economic spectrophotometric methods for the determination of desvenlafaxine in pure and its pharmaceutical formulations. In which proposed methods are based on the reaction of oxidative coupling of desvenlafaxine with 3-methyl-2benzthiazolinonehydrazone (Method A) and 2, 2' bipyridyl (Method B) in the presence of ferric chloride. The colored complex produced was measured at $663 \mathrm{~nm}, 522 \mathrm{~nm}$ for method A and B, respectively, against the reagent blank. The optimum experimental parameters for the color productions are selected. Bagga et al. [10] developed that simple and cost-effective colorimetric method is described for the determination of prasugrel in pure form and pharmaceutical formulations. The determination of the drug in pharmaceutical formulations is based on the drugs redox reaction with Folin-Ciocalteu reagent (Phenol reagent). The linearity range for prasugrel of blue chromogen produced at a wavelength of detection $725 \mathrm{~nm}$ was obtained as $10-50 \mu \mathrm{g} / \mathrm{ml}$. The absorbance was found to increase linearly with increasing concentration of prasugrel, which is corroborated by the calculated correlation coefficient value of 0.999 . Another simple, economical, precise, and reliable spectrophotometric method was done by Harshini et al. [11] for the estimation of prasugrel. In this method, the formation of chloroform extractable complex of prasugrel with bromocresol green this shows absorbance maximum at $418 \mathrm{~nm}$. Sowndarya et al. [12] developed a simple and cheap UV-spectrophotometric method for the quantitative estimation of dabigatrn etexilate $(150 \mathrm{mg})$ in capsules and the optimized method uses $0.05 \mathrm{~N} \mathrm{HCl}$ as a solvent for the estimation of an assay of dabigatrn etexilate in capsules at a wavelength of $325 \mathrm{~nm}$. The developed method resulted in dabigatrn etexilate exhibiting linearity in the range $5-15 \mu \mathrm{g} / \mathrm{ml}$. The assay precision is exemplified by the relative standard deviation of $1.4 \%$. Seshamamba and Sekaran [13] studied and revealed the report on the development of two spectrophotometric methods ( $\mathrm{A}$ and $\mathrm{B}$ ), for the determination of rivaroxaban in bulk and Xarelto tablets. Method A involves the formation of colored tris (1, 10-phenanthroline)-iron (II) complex, on reaction of rivaroxaban with iron (III)-1, and 10-phenanthroline mixture in acidic media. The colored complex is spectrophotometrically measured at $525 \mathrm{~nm}$. Method B involves the interaction of rivaroxaban with acetaldehyde with chloranil, to give colored vinyl amino substituted quinones. The colored product exhibit absorption maxima at $655 \mathrm{~nm}$. Beer's law correlating the absorbance with rivaroxaban concentration was obeyed 
in the range of 5-62.5 $\mu \mathrm{g} / \mathrm{ml}$ and $10-100 \mu \mathrm{g} / \mathrm{ml}$, for methods A and B, respectively. Alvi et al. [14] developed two simple, accurate, and precise UV derivative spectrophotometric methods for the simultaneous determination of prasugrel and aspirin in synthetic mixture form. The first method involves the measurement of second-order derivative spectra of prasugrel and aspirin. The zero crossing wavelengths $267.62 \mathrm{~nm}$ and $252.40 \mathrm{~nm}$ were selected for estimation of prasugrel and aspirin, respectively. In the second method, the first-order derivatives of ratio spectra were calculated and used for the determination of prasugrel and aspirin by measuring the peak intensity at $268 \mathrm{~nm}$ and $290 \mathrm{~nm}$, respectively. Çelebier et al. [15] studied that a UV-spectrophotometric method was developed for the determination of rivaroxaban content in pharmaceutical formulations and the amount of rivaroxaban released in tablet dissolution studies. The dissolution profile of rivaroxaban was successfully determined with the validated method. Sharaf et al. [16] created three rapid, accurate, and very simple derivative spectrophotometric methods for rivaroxaban and clopidogrel assay in their binary mixture and tablet dosage forms were developed. Method (I) is the first derivative spectrophotometric method; derivative amplitudes were measured at the zero crossing wavelength of 289 and $249.5 \mathrm{~nm}$ for estimation of rivaroxaban and clopidogrel, respectively. Method (II) is a ratio derivative spectrophotometric method. The ratio spectra of each drug were derived by dividing its spectra on a constant concentration of the other drug as a divisor. Derivative amplitudes were measured at $256 \mathrm{~nm}$ for rivaroxaban and at $214.5 \mathrm{~nm}$ for clopidogrel and in Method (III) is absorbance ratio method, the absorbance of both drugs was recorded at two wavelengths $\lambda 1$ (232) iso-absorptive point and $\lambda 2$ (249) $\lambda$ max of rivaroxaban and clopidogrel. Rajendiran et al. [16] developed new analytical methods such as UV Spectroscopy and reversed-phase high-performance liquid chromatographic (RP-HPLC) for the estimation of prasugrel hydrochloride in bulk and tablet dosage form. In the spectroscopic method, prasugrel hydrochloride showed maximum absorbance at $252 \mathrm{~nm}$ in methanol which is selected as a solvent for analysis based on its stability. Beer's law obeyed in the concentration range of $10-60 \mathrm{mcg} / \mathrm{ml}$. In RP-HPLC, the mobile phase selected is acetonitrile: trifluroacetic acid in the ratio $45: 55 \% \mathrm{v} / \mathrm{v}$. The flow rate was $0.1 \mathrm{ml} / \mathrm{min}$. The linearity range was found to be $10-60 \mathrm{mcg} / \mathrm{ml}$. The formulation EFIPLT was selected for analysis and the amount present was found to be $100.53 \%$ and $106.95 \%$ for method UV and RP-HPLC, respectively. Mehta and Maheshwari [17] developed UV-spectrophotometric methods and LC assay methods and validated for the determination of rivaroxaban and ticagrelor in the synthetic mixture. Spectrophotometric estimation was done by derivative spectroscopic method and methanol as solvent. In this method, $\lambda$ max for rivaroxaban and ticagrelor were selected at $295 \mathrm{~nm}$ and $249 \mathrm{~nm}$. RPHPLC analysis was carried out using Pearless C-18 column $(4.6 \times 250 \mathrm{~mm}$, $5 \mu$ particle size) and mobile phase composed of acetonitrile: $10 \%$ orthophosphoric acid in water $\mathrm{pH} 4.0(60: 40 \% \mathrm{v} / \mathrm{v})$ at a flow rate of $1.0 \mathrm{ml} / \mathrm{min}$ and chromatogram was recorded at $249 \mathrm{~nm}$.

\section{Chromatography}

Today not a single molecule is analyzed without the use of powerful analytical tools such as HPLC, ultra-performance LC (UPLC), and highperformance thin-layer chromatography (HPTLC).

Geetharam et al. [18] developed simple, precise, accurate, and rapid stability indicating that HPLC method was developed and validated for the determination of dabigatran etexilate in bulk and capsule dosage forms. Chromatographic separation was achieved using mobile phase phosphate buffer $\mathrm{Ph} 4.5$ and acetonitrile in the ratio 50:50 with hypersil BDS $\mathrm{C}_{18}(150 \times 4.6 \mathrm{~mm}, 5 \mu \mathrm{m})$ as stationary phase. Flow rate was optimized to $1.2 \mathrm{ml} / \mathrm{min}$ and effluents were monitored at $230 \mathrm{~nm}$. The retention time was around 3.19. Linearity was observed over a concentration range of $9-113 \mu \mathrm{g} / \mathrm{ml}$ with correlation coefficient of 0.999. Abdallah et al. [19] developed and validated an orthogonal stability-indicating testing protocol (RP-HPLC and NP-TLCdensitometry) for the quantification of Rivaroxaban. It is an amide group-containing oral anticoagulant was subjected to stress conditions commonly required for the registration of pharmaceuticals: base and acidcatalyzed hydrolysis $\left(0.1 \mathrm{M}, 60^{\circ} \mathrm{C}, 3-6 \mathrm{~h}\right)$, oxidation $(10 \% \mathrm{H} 2 \mathrm{O} 2,24$ h), photodegradation (300-800 $\mathrm{nm}, 24 \mathrm{~h}$ ) and thermal decomposition $\left(50^{\circ} \mathrm{C}, 6 \mathrm{~h}\right)$. Two major degradation products were separated and identified using TLC and LC/MS/MS, respectively. The Determination was carried out over a concentration range of $(5.00-50.00 \mu \mathrm{g} / \mathrm{mL})$ and $(0.40-12.00 \mu \mathrm{g} / \mathrm{band})$ with an accuracy of $(100.81 \% \pm 1.03)$ and $(100.29 \% \pm 1.08)$ for HPLC and TLC-densitometry, respectively. Nagadeep et al. [20] developed and validated RP-HPLC method for separation and determination of potential related impurities (starting materials and by-products of synthesis, and degradants) of dabigatran etexilate drug substance. The separation was accomplished on an Inertsil ODS 3V $(250 \mathrm{~mm} \times 4.6 \mathrm{~mm}, 5 \mu \mathrm{m})$ column connected to a photodiode array (PDA) detector using $20 \mathrm{mM}$ ammonium formate with $0.1 \%$ of triethylamine (TEA) (pH: 5.0 adjusted with formic acid) as mobile phase- $\mathrm{A}$ and acetonitrile as mobile phase- $\mathrm{B}$, under gradient elution. Kumar et al. [21] developed a RP-HPLC bioanalytical method development and validation for prasugrel in human plasma using PDA detector. The HPLC separation was carried out in an isocratic mode on an X-Terra C18 column $(4.6 \times 150 \mathrm{~mm} ; 5 \mu \mathrm{m})$ with a mobile phase consisting of potassium dihydrogen phosphate [pH 3.0] and acetonitrile in the ratio of $30: 70 \mathrm{v} / \mathrm{v}$ at a flow rate of $1.0 \mathrm{~mL} / \mathrm{min}$. The run time was maintained for $5 \mathrm{~min}$ and the detection was monitored at $210 \mathrm{~nm}$. Damle and Bagwe [22] developed and validated a simple, selective, and rapid stability indicating RP-HPLC method for the estimation of dabigatran etexilate analyte and it was resolved on a Neosphere C8 (150 $\mathrm{mm} \times 4.6 \mathrm{~mm}$ ) column. The mobile phase consisted of methanol: phosphate Buffer $(0.01 \mathrm{M} \mathrm{pH} 3)$ in the ratio of $60: 40 \mathrm{v} / \mathrm{v}$ and sonicated to degas. It was delivered at a flow rate of $1 \mathrm{ml} / \mathrm{min}$ at ambient temperature and the retention time was about $4.4 \pm 0.05 \mathrm{~min}$. Studies were performed on an HPLC system equipped with a PDA detector at $225 \mathrm{~nm}$. Ishaq et al. [23] designed to develop and validate a simple, sensitive, precise, and specific RP-HPLC method for the determination of prasugrel in bulk and its tablet dosage forms. Separation was carried out by RP chromatography on an inertsil ODS-3V column $(5 \mu \mathrm{m}$; $250 \times 4.6 \mathrm{~mm}^{2}$ ) with a mobile phase composed of $0.02 \mathrm{M}$ potassium dihydrogen orthophosphate, $0.02 \mathrm{M}$ dipotassium hydrogen orthophosphate in water: acetonitrile $(30: 70 \mathrm{v} / \mathrm{v})$ in isocratic mode at a flow rate of $1 \mathrm{ml} / \mathrm{min}$. The detection was monitored at $210 \mathrm{~nm}$. Sagar et al. [24] developed a rapid, simple, precise, accurate, and reproducible RP-HPLC method for simultaneous determination of aspirin and prasugrel in the tablet dosage form. The estimation was carried out on a HIBAR (Lichrospher C18) column with the dimensions of $250 \mathrm{~mm} \times 4.6 \mathrm{~mm}, 5 \mu \mathrm{m}$. Combination of acetonitrile and $0.5 \%$ potassium dihydrogen phosphate buffer (adjusted to $\mathrm{pH}-3$ using orthophosphoric acid) in the ratio of 60:40 was used as mobile phase. The flow rate is set at $1.0 \mathrm{ml} / \mathrm{min}$ and eluents were monitored at $220 \mathrm{~nm}$. Sahoo and Mekap [25] optimized a RP-HPLC procedure to finalize a different approach for the estimation of rivaroxaban in tablet dosage form. The determination was executed by $\mathrm{C}_{18}$ column (Phenomenex $250 \times 4.6 \mathrm{~mm}$, $5 \mu \mathrm{m}$ maintained at $35^{\circ} \mathrm{C}$ ) at $251 \mathrm{~nm}$ with a mobile phase (ACN: Water, $55: 45 \mathrm{v} / \mathrm{v}$ ) and flow of $1.2 \mathrm{ml} / \mathrm{min}$. The retention time found to be about 3.8 min. Manasa et al. [26] developed a rapid, sensitive, accurate, precise, and linear stability indicating RP-HPLC assay method and validate as per the ICH guidelines for the estimation of dabigatran etexilate mesylate in capsules. The optimized method employs a RP column, Phenomenex Kinetex EVO C18 $(250 \times 4.6 \mathrm{~mm}$; $5 \mu)$, a mobile phase of triethylammonium phosphate buffer $(\mathrm{pH}$ 2.0):methanol: acetonitrile in the proportion of 30:30:40 v/v, flow rate of $0.6 \mathrm{ml} / \mathrm{min}$ and a detection wavelength of $254 \mathrm{~nm}$ using a UV detector. Souri et al. [27] studied a stability-indicating HPLC method for the quantitative determination of rivaroxaban in pharmaceutical dosage forms. Rivaroxaban was subjected to acidic, basic, oxidative, photolytic, and thermal conditions for forced stress degradation studies. Considerable degradation was observed in all stress degradation tests. Rivaroxaban and its degradation products were separated on a Nova-Pak C8 column utilizing a mixture of acetonitrile and $\mathrm{KH}_{2} \mathrm{PO}_{4} 50 \mathrm{mM}(\mathrm{pH} 3.0)$ $(40: 60, \mathrm{v} / \mathrm{v})$ as the mobile phase, and the chromatogram was recorded at $270 \mathrm{~nm}$ using a general ultraviolet detector. Seshamamba et al. [28] developed simple and sensitive stability indicating HPLC method for 
the quantification of rivaroxaban in bulk and tablet dosage form. Chromatographic separation was achieved on an ACE-Ciano column ( $250 \mathrm{~mm} \times 4.6 \mathrm{~mm}, 5 \mu \mathrm{m}$ particle size). The mobile phase consists of 0.1 $\mathrm{M}$ sodium acetate and methanol $(60: 40 \mathrm{v} / \mathrm{v})$ and was delivered at a flow rate of $1 \mathrm{~mL} / \mathrm{min}$. A UV detector was used for detection. Reddy et al. [29] developed and validate RP-HPLC, simple, precise, accurate, and specific chromatographic method for the determination of related substances of prasugrel in pharmaceutical formulations. HPLC instrument and Inert Sustain C18, $75 \times 4.6 \mathrm{~mm}, 3 \mu \mathrm{m}$ were used for determination of prasugrel and its related substances. The buffer was prepared using $1.36 \mathrm{~g}$ of potassium phosphate monobasic in $1000 \mathrm{~mL}$ of water, adjust the $\mathrm{pH}$ of this solution to 3.30 with a dilute orthophosphoric acid solution and mix well. Filter through $0.45 \mu$ m nylon filter and degas. The buffer used as a mobile phase-A, the mobile phase-B was prepared by mixing acetonitrile and water in the ratio of $90: 10(\mathrm{v} / \mathrm{v})$. The flow rate of $1.0 \mathrm{~mL} / \mathrm{min}$ was set with gradient program, the temperature of the column compartment maintained at $30^{\circ} \mathrm{C}$ and ultraviolet detection done at $235 \mathrm{~nm}$ wavelength. Nawale et al. [30] developed and validate new, simple, and selective RP-HPLC method for the quantitative determination of dabigatran etexilate and its impurities in the pharmaceutical dosage form as per the ICH guidelines. Chromatographic analysis was performed on Princeton SPHER-100 C18 $(250 \times 4.6 \mathrm{~mm}, 5$ $\mu \mathrm{m}) \mathrm{HPLC}$ column, maintained at $50^{\circ} \mathrm{C}$ column temperatures, $6^{\circ} \mathrm{C}$ sample tray temperature, and detection monitored at $225 \mathrm{~nm}$. The mobile phase consisted of acetonitrile: phosphate buffer $(\mathrm{pH} 2.5)$ (33:67 V/V). The flow rate was maintained at $1.0 \mathrm{ml} / \mathrm{min}$. Bhavani et al. [31] developing simple, fast, and effective dissolution method for dabigatran etexilate mesylate capsules by RP-HPLC and validate as per the ICH guidelines. The optimized RP-HPLC method for dissolution studies uses a RP column, Phenomenex Luna C18 $(250 \times 4.6 \mathrm{~mm} ; 5 \mu)$, a mobile phase of triethylammonium phosphate buffer $(\mathrm{pH} 3.0)$ :acetonitrile in the proportion of $40: 60 \mathrm{v} / \mathrm{v}$, diluent as $0.01 \mathrm{~N}$ $\mathrm{HCl}$, flow rate of $1.0 \mathrm{ml} / \mathrm{min}$, injection volume as $20 \mu \mathrm{l}$, and a detection wavelength of $341 \mathrm{~nm}$ using a UV detector. Balaji et al. [32] developed a validated, simple, precise, and stability indicating RP-HPLC method for the determination of dabigatran etexilate mesylate in bulk drug and dosage form. LC separation was achieved gradient mode on a Zorbax SB $\left.\mathrm{C}_{18} 4.6 \times 150\right) \mathrm{mm}, 3.5 \mu \mathrm{m}$ column using mobile phase containing solution A $(2.72 \mathrm{~g}$ of potassium dihydrogen phosphate in $1000 \mathrm{ml}$ of water) PH 4.5 with orthophosphoric acid solution B (acetonitrile) at flow rate $1.0 \mathrm{ml} / \mathrm{min}$. The method employed a linear gradient elution and detection wavelength was set at $220 \mathrm{~nm}$. Bernardi et al. [33] developed and validated an RP-LC method for the determination of dabigatran etexilate in a capsule formulation. The LC method was carried out on a Zorbax C18 column $(250 \times 4.6 \mathrm{~mm}$ id $)$. The mobile phase consisted of acetonitrile and a solution of TEA $0.1 \%$, pH 6.0 adjusted with phosphoric acid $(65+35, \mathrm{v} / \mathrm{v})$ at a flow rate of $1.0 \mathrm{~mL} / \mathrm{min}$. The diode array detector was set at $225 \mathrm{~nm}$. The chromatographic separation was obtained with a retention time of $6.31 \mathrm{~min}$. Patel et al. [34] a simple and precise stability indicating that HPTLC method has been developed and validated for the simultaneous estimation of prasugrel and aspirin from dosage form. The method employed TLC aluminum plates precoated with silica gel 60 GF 254 as the stationary phase. The solvent system comprised carbon tetrachloride: ethyl acetate: acetic acid $(7.5: 2.4: 0.1, \mathrm{v} / \mathrm{v} / \mathrm{v})$. This system was found to give good result for both the drugs (Rf value: of aspirin $0.34 \mathrm{~cm}$ and Prasugrel $0.58 \mathrm{~cm}$ ). Spectrodensitometric scanning-integration was performed at a wavelength of $240 \mathrm{~nm}$. Avachat and Yamgar [35] developed and validated a RP-HPLC method for the estimation of rivaroxaban in bulk and tablet dosage forms. The separation was achieved on stainless steel Purospher ${ }^{\circledast}$ STAR Hibar ${ }^{\circledR}$ C18 analytical column $(250 \mathrm{~mm} \times 4.6 \mathrm{~mm}$ i.d., $5.0 \mu \mathrm{m}$ ) using acetonitrile and water in the ratio $80: 20 \mathrm{v} / \mathrm{v}$ as mobile phase and at a flow rate of $1 \mathrm{~mL} / \mathrm{min}$. Detection was carried out using a UV detector at $247 \mathrm{~nm}$. Liu et al. [36] detected a brand-new impurity by RP-HPLC in the prasugrel. The impurity was named as impurity X. Impurity $\mathrm{X}$ was isolated using semi-preparative HPLC followed by characterization using nuclear magnetic resonance spectroscopy and LC-MS. The functional mechanism of impurity $\mathrm{X}$ was speculated. Impurity $\mathrm{X}$ could be controlled in the manufacture process of the prasugrel active pharmaceutical ingredient effectively. BRC Sekhar Reddy and Nallagatla. Vijaya Bhaskar Rao. Reddy and Rao [37] validated that RP-HPLC is used for the estimation of dabigatran in bulk and pharmaceutical dosage form. It is a simple, precise, accurate RP-LC. The HPLC method has been carried out by using Chromasil C18 column. This method has been developed using the mobile phase consisting methanol: acetonitrile:water 80:15:5 (v/v). pH 4.7 at the flow rate of $1.0 \mathrm{ml} / \mathrm{min}$ by the detection of $\mathrm{UV}$ at $280 \mathrm{~nm}$. The retention time of the dabigatran is $5.73 \mathrm{~min}$. Ishaq et al [38] developed and validated a simple, sensitive, precise, and specific RP-HPLC method for the determination of prasugrel in bulk and tablet dosage forms. The HPLC separation was carried out by RP chromatography on inertsil ODS-3V column ( $5 \mu \mathrm{m} ; 250 \times 4.6 \mathrm{~mm}$ ) with a mobile phase composed of $0.02 \mathrm{M}$ potassium dihydrogen orthophosphate, $0.02 \mathrm{M}$ dipotassium hydrogen orthophosphate in water: acetronitrile $(30: 70 \mathrm{v} / \mathrm{v})$ in isocratic mode at a flow rate of $1 \mathrm{ml} / \mathrm{min}$. The detection was monitored at $210 \mathrm{~nm}$. Parmar et al. [39] developed RP-LC method for the assay of prasugrel in bulk. The chromatography was performed on Kromasil C18 column. The eluted compounds were monitored by UV detection at $257 \mathrm{~nm}$ using mobile phase methanol-potassium dihydrogen orthophosphate $(\mathrm{pH} 2.2 ; 10 \mathrm{mM})(70: 30, \mathrm{v} / \mathrm{v})$. Hadagali [40] developed and validated a simple, sensitive, and rugged RP-HPLC method for the determination of rivaroxaban in pure, pharmaceutical formulations, and in spiked human plasma sample. The separation of rivaroxaban and internal standard was achieved on XDB C18 $(150 \times 4.6) \mathrm{mm}$ column. Mobile phase employed for the study is the mixture of water and acetonitrile in gradient program. A flow rate of $1 \mathrm{ml} / \mathrm{min}$ was found optimum for the study. Srinivas et al. [41] developed a simple, precise, accurate, economical, and reproducible RP-HPLC method for estimation of dabigatran etexilate mesylate in capsule dosage form. Quantitative HPLC was performed with Shimadzu LC 20ATwith Spin chrome Software with UV-Visible Detector (SPD-20A), Phenomenex Luna C18, $5 \mu \mathrm{m}, 250 \times 4.6 \mathrm{~mm}$ (size) column was used in the study. The mobile phase of methanol: eater $(70: 30)$ used in this study. The conditions optimized were flow rate $(1.2 \mathrm{ml} / \mathrm{min})$ and wavelength $(230 \mathrm{~nm})$ and run time was $10 \mathrm{~min}$, column temperature was maintained at 500 C. Retention time was found to be $4.60 \mathrm{~min}$. Sonia et al. [42] developed and validated of prasugrel hydrochloride $5 \mathrm{mg}$ tablet by RPHPLC for precision, accuracy linearity, and robustness. Zorbax, SBPhenyl $250 \times 4.6 \mathrm{~mm}, 5 \mu$ in isocratic mode, with mobile phase containing buffer (pH 6.5 with TEA and potassium dihydrogen orthophosphate) acetonitrile: eater $(90: 10)[40-60(\mathrm{v} / \mathrm{v})]$ was used. The flow rate was $1.2 \mathrm{ml} / \mathrm{min}$ and the analyte was monitored at $235 \mathrm{~nm}$. The retention time for prasugrel HCL was 11.5 min. Dalmora et al. [43] a stability indicating that RP-HPLC method was validated for the analysis of rivaroxaban. The method was carried out on a C18 column ( $150 \mathrm{~mm} \times 4.6 \mathrm{~mm}$ i.d.), maintained at $40^{\circ} \mathrm{C}$. The mobile phase consisted of acetonitrile and water (70:30), run isocratically at a flow rate of $0.7 \mathrm{~mL} / \mathrm{min}$, and using a PDA detection at $249 \mathrm{~nm}$. The separation was obtained with retention time of 2.9 min. Prajapati and Patel [44] described a precise, accurate, and reproducible RP-HPLC method for simultaneous estimation of clopidogrel and rivaroxaban. The separation was carried by Kromasil C18 column $(250 \times 4.6 \mathrm{~mm}, 5 \mu)$ with UV detection at $240 \mathrm{~nm}$. The mobile phase is consisting of acetonitrile and water in a ratio of $90: 10, \mathrm{v} / \mathrm{v}$ and at a flow rate of $1 \mathrm{~mL} / \mathrm{min}$. The method was linear over the concentration range for clopidogrel 1.0-20.0 $\mu \mathrm{g} / \mathrm{mL}$ and for rivaroxaban $1.0-20.0 \mu \mathrm{g} / \mathrm{mL}$. Sriram et al. [45] described the development of RP-HPLC method for prasugrel hydrochloride in the presence of impurities and degradation products generated from the forced degradation studies. Successful separation of the drug from the process related impurities and degradation products were achieved on Gemini C18 $(250 \times 4.6 \mathrm{~mm}) 5 \mu \mathrm{m}$ particle size column using RP-HPLC method. The isocratic method employed with a mixture of buffer and $(10 \% \mathrm{v} / \mathrm{v}$ water in acetonitrile) mixture of ratio $30: 70$, respectively. Potassium dihydrogen orthophosphate $(0.05 \mathrm{M})$ is used as buffer. Kasad [46] developed and validated a simple, precise, and accurate RPHPLC method for assay of rivaroxaban. An isocratic separation was achieved using a phenomenex $\mathrm{C} 18(250 \times 4.6 \mathrm{~mm}, 5 \mu \mathrm{m}), 100^{\circ} \mathrm{A}$ particle size columns with a flow rate of $1 \mathrm{ml} / \mathrm{min}$ and using a PDA detector to 
monitor the elute at $250 \mathrm{~nm}$. The mobile phase consisted of methanol: acetronitrile (50:50 v/v). Raja et al. [47] developed and validated a simple, rapid, and reproducible RP-HPLC method for the estimation of prasugrel hydrochloride in tablet dosage form. A Zorbax, SB-Phenyl $250 \times 4.6 \mathrm{~mm}, 5 \mu$ in isocratic mode, with mobile phase containing buffer ( $\mathrm{pH} 6.5$ with TEA and potassium dihydrogen orthophosphate):acetonitrile: water (90:10) [40:60 (v/v)] was used. The flow rate was $1.2 \mathrm{ml} / \mathrm{min}$ and the analyte was monitored at $235 \mathrm{~nm}$. The retention time for prasugrel $\mathrm{HCl}$ was $11.5 \mathrm{~min}$. Rigobello et al. [48] a stability indicating that RP-LC method for the determination of prasugrel in tablets was developed and validated. Stress testing of prasugrel was carried out in accordance with ICH guidelines, where the drug was submitted to acidic and basic hydrolysis, oxidative, thermal, and photolytic conditions. Prasugrel was unstable under all the conditions and the degradations products were analyzed by HPLC-UV. Furthermore, two main degradation products found under alkaline and thermal conditions were investigated by LC-MS. Based on the fragmentation patterns, two products resulted from hydrolysis of the acetate ester moiety of prasugrel were observed. Due the chemical equilibrium, tautomerism occurs between the ketone and alcohol functions justifying the similar molecular weight and fragment pattern obtained in degradation products analysis. Successful separation was achieved on a RP-18 octadecylsilane column using acetonitrile and TEA $0.5 \%$ mixture $(50: 50, \mathrm{v} / \mathrm{v})$ as the mobile phase at $25^{\circ} \mathrm{C}$. The flow rate was $1.0 \mathrm{~mL} / \mathrm{min}$ and the detector wavelength was $263 \mathrm{~nm}$. Ahirrao et al. [49] developed a simple, rapid, and precise method for the quantitative estimation of prasugrel hydrochloride in pharmaceutical dosage form. A chromatographic separation of prasugrel and its degradants was achieved with Zorbax XDB C8, 150×4.6 mm, $3.5 \mu \mathrm{m}$ analytical column using aqueous solution of $0.05 \mathrm{M}$ ammonium acetate $\mathrm{pH} 4.5$ with acetic acid-acetonitrile $(40: 60 \mathrm{v} / \mathrm{v})$. The instrumental settings include flow rate of $1.0 \mathrm{ml} / \mathrm{min}$, column temperature at $30^{\circ} \mathrm{C}$, and detector wavelength of $254 \mathrm{~nm}$ using a PDA detector. Modi and Pingale [50] developed and validated a new, simple, specific, accurate, precise, and rapid RP-HPLC method for the determination of prasugrel hydrochloride in pure and tablet dosage forms. The HPLC separation was carried out by RP chromatography on Kromasil C18 $(100 \times 4.6 \mathrm{~mm}$; $5 \mu \mathrm{m}$ ) with a mobile phase consist of methanol buffer (680 mg potassium dihydrogen phosphate in $500 \mathrm{ml}$ water, $\mathrm{pH}-2.1$ adjusted with orthophosphoric acid) in the ratio of 70:30 v/v delivered in isocratic mode at a flow rate of $0.8 \mathrm{ml} / \mathrm{min}$. The prasugrel hydrochloride was quantified at $220 \mathrm{~nm}$. The retention time of prasugrel hydrochloride was 1.9 min. Kumar et al. [51] designed a simple, sensitive, precise, and specific RP-HPLC method for the determination of prasugrel in bulk and its tablet dosage forms. The HPLC separation was carried out by RP chromatography on XTerra column C18 $(4.6 \times 150 \mathrm{~mm}, 5 \mu \mathrm{m})$ with a mobile phase composed potassium dihydrogen phosphate and the $\mathrm{pH}$ has been adjusted to 3.0 by Orthophosporic acid and acetonitrile in the ration of 40:60 v/v in isocratic mode at a flow rate of $1.0 \mathrm{ml} / \mathrm{min}$. The run time has been maintained 5 min. The detection was monitored at $210 \mathrm{~nm}$. Shivashankar et al. [52] developed and validated a simple RP-HPLC method for the estimation of rivaroxaban in formulation. A HIBAR- $5 \mu$ C18 column $(250 \times 4.6 \mathrm{~mm})$ was used as a stationary phase. The mobile phase consisted of potassium dihydrogen orthophosphate buffer (pH adjusted to 3.0 with orthophosphoric acid):acetonitrile in the ratio of $60: 40 \% \mathrm{v} / \mathrm{v}$ and the flow rate was $1 \mathrm{ml} / \mathrm{min}$. The detection was carried in the room temperature at $248 \mathrm{~nm}$. The retention time of rivaroxaban was $7.45 \mathrm{~min}$. Latha et al. [53] developed and validated a RP-HPLC method for the determination of dabigatran etexilate mesylate (DEM) in bulk form. The chromatography was carried out on Unisol C18 $(4.6 \times 150 \mathrm{~mm}, 3 \mu \mathrm{m})$ using a mobile phase of methanol and ammonium acetate buffer in the ratio of $90: 10$, at a flow rate of $1 \mathrm{ml} / \mathrm{min}$. The analytes were monitored at $226 \mathrm{~nm}$ using a PDA detector. The retention time of the DEM was $2.52 \mathrm{~min}$. Dare et al. [54] developed the stability indicating, highly accurate precise and linear method for related substance of the dabigatran through the RP-HPLC. The optimize method uses a RP column, Poroshell 120 EC-18 (150 mm×4.6 mm, $2.7 \mu$ ), mobile phase of hexane- 1 sulfonic acid sodium salt monohydrate $(6.5 \pm 0.05)$, and methanol through gradient flow rate of $0.6 \mathrm{ml} / \mathrm{min}$.
Keeping the column at temperature $30^{\circ} \mathrm{C}$ and using the sample amount $10 \mu \mathrm{L}$ at $5^{\circ} \mathrm{C}$ and detected all the impurities at $230 \mathrm{~nm}$ by the UV detector. In the developed method, elution of dabigatran was at 26.9 min. El Zaher et al. [55] carried a simple, precise, accurate, and rapid stability indicating that LC method was developed for the determination of dabigatran etexilate mesylate in bulk powder and pharmaceutical formulations. Chromatographic separation was carried out by isocratic elution on Eclipse XDB C8 $(4.6 \times 250 \mathrm{~mm}, 5 \mu \mathrm{m})$ using $0.01 \mathrm{M}$ orthophosphoric acid ( $\mathrm{pH} 2.6)$ :acetonitrile $(60: 40 \mathrm{v} / \mathrm{v})$ as the mobile phase. The flow rate was $1.5 \mathrm{ml} / \mathrm{min}$ and the UV detection was done at $225 \mathrm{~nm}$. Linearity was obtained over a concentration range of $5-100 \mu \mathrm{g} / \mathrm{ml}$ with a regression coefficient of 0.9975 . Patel et al. [56] developed and validated an accurate, sensitive and rapid RP-HPLC method for the estimation of dabigatran etexilate mesylate from capsule dosage form. The separation was achieved by a Zorbax C18 column $(100 \mathrm{~mm} \times 4.6 \mathrm{~mm}, 3.5 \mu \mathrm{m})$ in isocratic mode, with mobile phase comprises of acetonitrile: water in the proportion of 70:30 v/v. The flow rate of mobile phase was $1.0 \mathrm{ml} / \mathrm{min}$, and detection was done at $225 \mathrm{~nm}$ wavelength. The retention time of dabigatran etexilate mesylate was $3.0 \mathrm{~min}$. The calibration curve was found to be linear with in the concentration range of $20 \mu \mathrm{g} / \mathrm{ml}-100 \mu \mathrm{g} / \mathrm{ml}$. Çelebier et al. [57] developed a RP-HPLC method for the determination of rivaroxaban in tablets (Xarelto ${ }^{\circledR}[10 \mathrm{mg}]$ ). Phenomenex Luna $5 \mu \mathrm{m}$ C18 $100 \AA$ LC Column $(250 \times 4.6 \mathrm{~mm})$ was used at $40^{\circ} \mathrm{C}$. Isocratic elution was performed with ACN: water (55:45 v/v) mixture. The flow rate was $1.2 \mathrm{~mL} / \mathrm{min}$ and UV detection was at $249 \mathrm{~nm}$. Internal standard (Caffeine) and rivaroxaban were eluted within 2.21 and $3.37 \mathrm{~min}$, respectively. Girase and Soni [58] developed and validated RP-HPLC method for the qualitative analysis of rivaroxaban. The chromatographic separation was achieved on ZorbaxSB C18 $(250 \mathrm{~mm} \times 4.6 \mathrm{~mm}, 3.5 \mu)$ HPLC column using buffer $(0.02 \mathrm{M}$ mono basic potassium dihydrogen phosphate) and solvent mixture (acetonitrile: methanol mixture) ingradient program. Rajan and Basha [59] developed and evaluated the RP-UPLC method for the quantitative determination of potential impurities of rivaroxaban active pharmaceutical ingredient. The method uses a water acquity BEH C8 column $(100 \mathrm{~mm} \times 2.1 \mathrm{~mm}, 1.7 \mu \mathrm{m})$ with mobile phase A consisted, $0.05 \mathrm{M}$ diammonium hydrogen phosphate, pH adjusted to 3.0 and acetonitrile $(80: 20, \mathrm{v} / \mathrm{v})$, and mobile phase B consisted mixture of acetonitrile and water $(90: 10, v / v)$ with a gradient program. The column temperature was maintained at $30^{\circ} \mathrm{C}$ and the detection was carried out at $254 \mathrm{~nm}$. El-Aziz et al. [60] created simultaneous assay method of two anti-platelet drugs, rivaroxaban with clopidogrel the developed and validated method is characterized by its simplicity, sensitivity, and rapidness. Chromatographic study is performed on a $3 \mathrm{~mm} \times 4.6 \mathrm{~mm}$ i.d., $2 \mu \mathrm{m}$ pore size highly porous monolithic (Chromolith ${ }^{\circledR} \mathrm{RP}$ ) column to obtain good chromatographic separation using a mixture of $0.185 \mathrm{M}$ sodium dodecylsulfate, $8 \%$ $\mathrm{n}$-propanol, $0.3 \%$ TEA as a mobile phase, and adjusted at $\mathrm{pH} 4.0 \mathrm{using}$ $0.02 \mathrm{M}$ orthophosphoric acid and pumped at a flow rate of $1 \mathrm{~mL} / \mathrm{min}$ using UV detector at $235 \mathrm{~nm}$. The internal standard (IS) of choice was raloxifen and separation was performed at room temperature. Good linearity for the proposed method was obtained over the ranges of 0.3$9.0 \mu \mathrm{g} / \mathrm{mL}$ and $0.5-25.0 \mu \mathrm{g} / \mathrm{mL}$ and retention time was 1.9 and $5 \mathrm{~min}$, respectively. Meenakshi and Rao [61] developed that simple, rapid, accurate, precise, robust, and reproducible RP-HPLC method for the determination of rivaroxaban in pure drug and pharmaceutical dosage form. The quantification was carried out using enable $\left.\mathrm{C}_{18} 250 \times 4.6 \mathrm{~mm}, 5 \mu \mathrm{m}\right)$ column in a binary mode with mobile phase comprising $0.1 \%$ glacial acetic acid: acetonitrile in $30: 70 \% \mathrm{v} / \mathrm{v}$ at flow rate $1 \mathrm{ml} / \mathrm{min}$, detection was carried out at $250 \mathrm{~nm}$ using PDA detector with injection volume $20 \mu \mathrm{l}$, the retention time was found to be $3.44 \mathrm{~min}$. Sahani and Jain [62] developed and validate a simple, rapid, accurate, and precise RP-HPLC method for simultaneous estimation of drotaverine hydrochloride, ethamsylate, and tranexamic acid in the tablet dosage form. Sunny et al. [63] developed RP-HPLC method for the quantitative estimation of rivaroxabanin formulation and bulk drug. Isocratic elution at a flow rate of $1 \mathrm{ml} / \mathrm{min}$ was employed on an Aglient Eclipse C8 LC Column $(150 \times 4.6 \mathrm{~mm})$ with $5 \mu \mathrm{m}$ pore size was used at $40^{\circ} \mathrm{C}$. The mobile phase consisted of TEA: acetonitrile 85:15 v/v $\left(\mathrm{P}^{\mathrm{H}}\right.$ 
11.6). The UV detection wavelength was at $251 \mathrm{~nm}$ and $20 \mu \mathrm{l}$, the sample was injected at an interval of $5 \mathrm{~min}$. Retention time for rivaroxaban was $1.56 \mathrm{~min}$. Prajapati et al. [64] carried stabilityindicating HPTLC method for the estimation of dabigatran etexilate mesylate using TLC plates pre-coated with silica gel 60 F254 as stationary phase and toluene: ethyl acetate: methanol:formic acid (3:4:3:0.2, v/v/v/v) as the mobile phase. The wavelength selected for quantitation was $314 \mathrm{~nm}$. The method was linear in the concentration range $50-250 \mathrm{ng} / \mathrm{spot}$ with a correlation coefficient of 0.9955 . Vaghela and Patel [65] developed and validated HPTLC, simple, precise, accurate, and specific chromatographic method for the determination of rivaroxaban from its tablet dosage form. The mention drug was spotted on silica gel F254 TLC plates under pure nitrogen stream by Linomat TLC spotter. Separation was carried out using methanol, toluene, and triethanolamine as mobile phase in ratio of 7:2.5:0.5 v/v/v. Developed TLC plates were scanned by CAMAG TLC scanner and detection was carried out at $249 \mathrm{~nm}$. Rf value of separated drug was found to be 0.60 for rivaroxaban. The linearity of rivaroxaban is $500-$ $3000 \mathrm{ng} / \mathrm{spot}$. Srikanth et al. [66] proposed that simple, sensitive and precise RP-HPLC method has been developed for the estimation of prasugrel hydrochloride in pharmaceutical dosage forms. The mobile phase consist of buffer ( $0.02 \mathrm{M}$ sodium dihydrogen phosphate, $\mathrm{pH}-3$ adjusted with orthophosphoric acid):methanol: acetonitrile in the ratio of $45: 20: 35 \mathrm{v} / \mathrm{v}$ delivered at a flow rate of $1.0 \mathrm{ml} / \mathrm{min}$ and wavelength of detection at $220 \mathrm{~nm}$. The retention time of prasugrel hydrochloride was $8.2 \mathrm{~min}$. Abu Ruzilawati and Miran [67] discussed and developed that methamphetamine is one of the illicit drugs, which are common among students and teenagers. Methamphetamine was found to be the most commonly abused amphetamine-type stimulants compared with other types of amphetamines. Therefore, fast and reliable detection of these drugs is important in toxicology and doping control. Many extraction methods such as solid phase (SPE) and SPE microextraction have been used for extraction of methamphetamine in the biological fluid. The objective of this study was to develop an effective liquid-liquid extraction method form ethamphetamine in human urine. Optimization of the extraction method was done by varying the types of solvents used to extract the drug from the urine. The percentage recovery of methamphetamine extraction was investigated using a variety of extracting solvents (ethyl acetate, dichloromethane, diethyl ether, and chloroform) and solvents system (chloroform: isopropanol [9:1] and chloroform: ethyl acetate: ethanol [3:1:1]). The analysis of the extracted drug was done by HPLC equipped with fluorescence detector. Optimization of chromatographic conditions was also done by varying the pH's of mobile phase and the composition of the mobile phase. The extracting solvent system that consists of chloroform: ethyl acetate: ethanol $(3: 1: 1)$ gave the highest recovery, which is $87 \%$. The optimized HPLC condition used for the analysis was a mixture of acetonitrile and deionized water at $\mathrm{pH} 2.4$ in the ratio of $15: 85 \mathrm{v} / \mathrm{v}$ with a flow rate of $0.6 \mathrm{~mL} / \mathrm{min}$.

\section{LC-MS}

Antovic et al. [68] carried that dabigatran concentration in plasma was determined using LC-MS/MS. Chromatographic separation of the analytes was achieved on an Acquity UPLC BEH column (Shield $\mathrm{RP}_{18}$, $2.1 \times 50 \mathrm{~mm}, 1.7 \mu \mathrm{m})$ using a gradient run with mobile phase A $(10 \mathrm{mM}$ ammonium formate $\mathrm{pH} 4.5)$ and mobile phase B $(0.1 \%$ formic acid in acetonitrile). The analytes were detected using a Waters Quattro Premier XE mass spectrometer operating in positive electrospray ionization (ESI) mode, utilizing selected reaction monitoring (SRM) with ion transitions $472 \rightarrow 289 \mathrm{~m} / \mathrm{z}$ for dabigatran and $475 \rightarrow 292 \mathrm{~m} / \mathrm{z}$ for the internal standard. The total analysis time was $3 \mathrm{~min}$. Srikanth and Rani [69] developed and validate a LC-MS/MS for the quantification of lenvatinib (LT) in human plasma. A simple, sensitive, and specific LC-MS/MS method was developed for quantification of LT in human plasma using LTD4 as internal standard (IS). The analytical method consists of liquid-liquid extraction of plasma sample followed by the determination of LT by an LC-MS/MS. The analyte was separated on a Zorbax Eclipse XDB-C18 $(150 \times 4.6 \mathrm{~mm}, 5 \mu)$ column with an isocratic mobile phase of acetontrile: $0.1 \%$ formic acid $(80: 20 \mathrm{v} / \mathrm{v})$ at a flow rate of $0.6 \mathrm{~mL} / \mathrm{min}$. The product ions were formed by a turbo lon spray in a positive mode were used to detect analyte and IS. The MS/MS detection was made by monitoring the fragmentation of $\mathrm{m} / \mathrm{z} 427.10 \rightarrow 370.10$ for LT and m/z $430.30 \rightarrow 370.10$ for IS on a MS. Schmitz et al. [70] carried out determination of dabigatran, rivaroxaban, and apixaban by UPLCMS/MS and coagulation assays for therapy monitoring of novel direct oral anticoagulants. Zhang et al. [71] established a rapid and sensitive UPLC-MS/MS method for the determination of rivaroxaban, apixaban, and edoxaban in rat plasma. The analytes and the internal standard (diazepam) were separated on an Acquity UPLC BEH C ${ }_{18}$ chromatography column $(2.1 \mathrm{~mm}, 9.50 \mathrm{~mm}, 1.7 \mu \mathrm{m})$ using gradient elution with a mobile phase of acetonitrile and $0.1 \%$ formic acid in water at a flow rate of $0.4 \mathrm{~mL} / \mathrm{min}$. The detection was performed on a triple quadrupole MS/ MS by multiple reaction monitoring mode to monitor the precursor-toproduct ion transitions of $\mathrm{m} / \mathrm{z} 436.1 \rightarrow 145.1$ for rivaroxaban, $\mathrm{m} / \mathrm{z} 460.0$ $\rightarrow 443.1$ for apixaban, $\mathrm{m} / \mathrm{z} 548.2 \rightarrow 366.1$ for edoxaban, and $\mathrm{m} / \mathrm{z} 285.2 \rightarrow$ 193.1 for diazepam (IS) using a positive ESI interface. The method was validated over a concentration range of $1.0-200 \mathrm{ng} / \mathrm{mL}$ for rivaroxaban, $1.0-100 \mathrm{ng} / \mathrm{mL}$ for apixaban, and $1.0-500 \mathrm{ng} / \mathrm{mL}$ for edoxaban. Total time for each chromatograph was $3.5 \mathrm{~min}$. Reddy et al. [72] developed and validated a HPLC-MS/MS technique for the determination of rivaroxaban in human plasma. The samples were extracted using solid-phase extraction (SPE) technique wherein rivaroxaban D4 has been used as the internal standard. The use of isocratic LC method has enabled to achieve $2.0 \mathrm{~min}$ along with their respective internal standard using a Phenomenex Gemini $\mathrm{C}_{18}, 50 \times 4.6 \mathrm{~mm}, 5 \mu \mathrm{m}$ column. ESI source in positive mode was used for the detections of rivaroxaban and IS. Precursor to product ion transition of $\mathrm{m} / \mathrm{z} 436.20 \rightarrow 144.80$ for rivaroxaban and $\mathrm{m} / \mathrm{z} 440.20 \rightarrow 144.70$ for IS was used in multiple reaction monitoring mode. Derogis et al. [73] proposed that a HPLCMS/MS method was validated to measure rivaroxaban plasmatic concentration. In this method used a simple sample preparation, protein precipitation, and a fast chromatographic run. It was developed a precise and accurate method, with a linear range from 2 to $500 \mathrm{ng} / \mathrm{mL}$, and a lower limit of quantification of $4 \mathrm{pg}$ on column. The new method was compared to a reference method (anti-factor Xa activity) and both presented a good correlation $(\mathrm{r}=0.98, \mathrm{p}<0.001)$. In addition authors are validated hemolytic, icteric or lipemic plasma samples for rivaroxaban measurement by HPLC-MS/MS without interferences. The chromogenic and HPLC-MS/MS methods were highly correlated and should be used as clinical tools for drug monitoring. Puram et al [74] evaluated the levels in plasma of pyridostigmine impurity B (metabolite of pyridostigmine) in humans after administration of pyridostigmine formulations. Plasma concentrations of pyridostigmine impurity B were estimated using by LC coupled with ESI triple quad mass spectrometer technique, lamivudine is used as an internal standard. Multiple reactions at 109.9/95.2 (pyridostigmine impurity B) and 230.2/112.2 (lamivudine) were monitored. Chromatography was optimized using acetonitrile: buffer (10 millimolar ammonium acetate) (85:15) on an Inertsil C18, $150 \mathrm{~mm} \times 4.6 \mathrm{~mm}, 5 \mu$ analytical column. The Linear Calibration curve was ranges between $1.434 \mathrm{ng} / \mathrm{ml}$ and $39.637 \mathrm{ng} / \mathrm{ml}$. Sample extraction was conducted using SPE extraction method using mixed mode cation exchange cartridges. The method was developed on API 4000. The method was developed, tested for system suitability, carryover, selectivity, matrix effect, intra-inter precision and accuracy, recovery, linearity, and various stabilities in aqueous as well as plasma as a matrix. The method was validated for all the above validation parameters mentioned as per European medical agency guideline on method validation. Yadav and Dubey [75] successfully developed a sensitive and accurate LC method for the quantification of rivaroxaban in human plasma. Protein precipitation was used for sample preparation. Quantification of analyte was achieved on phenomenex luna $C_{8}(5 \mu \mathrm{m} \times 25 \mathrm{~cm} \times 4.6 \mathrm{~mm}$ i.d. $)$ column using methanol: water:dimethyl sulfoxide (50:45:5, v/v/v) as mobile phase at a flow rate of $1 \mathrm{ml} / \mathrm{min}$. Detection was achieved at $252 \mathrm{~nm}$ over the linearity concentration range of 5-40 $\mu \mathrm{g} / \mathrm{ml}$. Retention time was found $6.2 \mathrm{~min}$. The Limit of detection and limit of quantification were found to be $1.5 \mu \mathrm{g} / \mathrm{ml}$ and $4.5 \mu \mathrm{g} / \mathrm{ml}$, respectively. The developed method was validated as per the US FDA guidelines. 


\section{CONCLUSION}

Most of the techniques such as spectrophotometric and chromatography RP-HPLC and LC coupled with MS/MS methods have been applied when dabigatran, rivaroxaban, and prasugrel are in pure form and its formulations. As far as, we know there is not a single research paper which refers to the quantification of dabigatran, rivaroxaban, and prasugrel by applicability quality by design. Hence, there is still scope for the development of new selective and specific analytical techniques for quantization of these molecules.

\section{REFERENCES}

1. Tripathi KD. Essentials of Medical Pharmacology. $6^{\text {th }}$ ed. Jaypee Brothers Medical Publishers (P) Ltd.; 2008. p. 597-605.

2. Jayavarapu KR, Satyanarayana T, Baby B, Kesavarao CH, Sujatha K, Ramya K, et al. Validated UV-spectroscopic method for the estimation of dabigatran etexilate mesylate in formulation and tablet dosage form. Indo Am J Pharm Res 2016;6:4952-6.

3. Prajapati A, Kumar S, Sen AK, Zanwar A, Seth AK. Spectrophotometric method for estimation of dabigatran etexilate in bulk and its pharmaceutical dosage form. Pharm Sci Monit 2014;5:31-9.

4. Hepsebah NJ, Kumar AA. Spectrometric dissolution method for dabigatran etexilate mesylate capsules. World J Pharm Pharm Sci 2018;7:1277-90.

5. Harini U, Madhavilatha N, Pawar AK. Development and validation of UV spectrophotometric method for the estimation of dabigatran etexilate mesylate (dem). Int J Pharm Anal Res 2016;5:218-23.

6. El-Din MS, Ibrahim F, Shalan SH, El-Aziz HA, Spectrophotometric methods for simultaneous determination of rivaroxaban and clopidogrel in their binary mixture. Pharm Anal Acta 2018:9:1-9.

7. Seshamamba BS, Sekaran CB, Spectrophotometric quantification of direct factor xa inhibitor, rivaroxaban, in raw and tablet dosage form. Glob Drugs Ther 2017;2:1-8.

8. Sekaran CB, Bind VH, Damayanthi MR, Sireesha A. Development and validation of UV spectrophotometric method for the determination of rivaroxaban. Der Pharm Chem 2013;5:1-5.

9. Sreeja U, Gurupadayya BM, Chandan RS, Novel spectrophotometric methods for the quantification of desvenlafaxine in pure and pharmaceutical dosage form. Asian J Pharm Clin Res 2015;8:267-70.

10. Bagga P, Khan MS, Siddiqui MH, Mahmood T, Siddiqui HH, Colorimetric estimation of prasugrel in bulk and pharmaceutical formulations. Int J Curr Res 2011;3:418-20.

11. Harshini B, Alekhya SV, Manasa G, Prakash KV, Extractive spectrophotometric estimation of prasugrel in pharmaceutical formulation. Res J Pharm Biol Chem Sci 2011;2:426-30.

12. Sowndarya P, Mounika K, Prasanna SL, Sandya K, Kumar AA. Assay method development and validation of dabigatrn etexilate in capsules by UV spectroscopy. Int J Pharm Pharm Sci 2015;7:282-5.

13. Seshamamba BS, Sekaran CB. Spectrophotometric analysis for the quantification of rivaroxaban in bulk and tablet dosage form. Int J Med Pharm Sci 2017;7:21-34.

14. Alvi SN, Patel MN, Kathiriya PB, Patel BA, Parmar SJ. Simultaneous determination of prasugrel and aspirin by second order and ratio first order derivative ultraviolet spectrophotometry. J Spectrose 2013;2013:1-7.

15. Celebier M, Kaynak MS, Altıöz S, Sahin S. UV Spectrophotometric method for determination of the dissolution profile of rivaroxaban. Dissolution Technol 2014;21:56-9.

16. Rajendiran RK, Sekar VK, Namadevan BD, Annamalai JK, Devarajan S. UV-spectrophotometric and RP-HPLC methods for the estimation of prasugrel hydrochloride in bulk and tablet formulation. Int J Pharm Pharm Sci 2014;6:220-5.

17. Mehta AR, Maheshwari DG. Development and validation of first UV spectrophotometric method and RP-HPLC method for simultaneous estimation of rivaroxaban and ticagrelor in synthetic mixture. J Glob Trends Pharm Sci 2018;9:5275-97.

18. Geetharam Y, Mallesh M, Gupta VR, Sridhar B, Srividya E, Subhash S. Validated stability-indicating liquid chromatographic method for the determination of dabigatran etexilate (thrombin inhibitor) in capsules. Indo Am J Pharm Res 2014;4:2141-50.

19. Abdallah MA, Al-Ghobashy MA, Lotfy HM. Investigation of the profile and kinetics of degradation of rivaroxaban using HPLC, TLCdensitometry and LC/MS/MS: Application to pre-formulation studies. Bull Fac Pharm Cairo Univ 2015;53:53-61.

20. Nagadeep J, Kamaraj P, Arthanareeswari M. Gradient RP-HPLC method for the determination of potential impurities in dabigatran etexilate in bulk drug and capsule formulations. Arab J Chem 2015;30:1-13.

21. Kumar SA, Debnath M, Rao JS, Sankar DG. Validation of developed method by RP-HPLC for estimation of prasugrelin human plasma and studying the stability of the drugs in plasma. Kathmandu Univ J Sci Eng Technol 2017;13:65-75.

22. Damle MC, Bagwe RA. Development and validation of stabilityindicating RP-HPLC method for estimation of dabigatran etexilate. J Adv Sci Res 2014;5:39-44.

23. Ishaq BM, Prakash KV, Mohan GK. Analytical method development and validation of prasugrel in bulk and its pharmaceutical formulation using the RP-HPLC method. Pharm Methods 2011;2:173-7.

24. Sagar PV, Samidha MT, Krishna V, Rani SS. A validated RP-HPLC method for simultaneous estimation of aspirin and prasugrel in tablet dosage form. Int J Pharm Sci Res 2014;5:4858-64.

25. Sahoo S, Mekap SK. Assay comparison of rivaroxaban by new HPLC method with an existing method in tablet dosage form. Pharm Biol Eval 2017:4:180-2

26. Manasa P, Sowndarya P, Mounika K, Kumar AA. A rapid stability indicating RP-HPLC assay method development and validation for the quantitative estimation of dabigatran etexilate mesylate in capsules. Indo Am J Pharm Sci 2015;2:1382-92.

27. Souri E, Mottaghi S, Zargarpoor M, Ahmadkhaniha R, Jalalizadeh H. Development of a stability-indicating HPLC method and a dissolution test for rivaroxaban dosage forms. Acta Chromatogr 2016;28:347-61.

28. Seshamamba BS, Satyanarayana PV, Sekaran CB. Application of stability indicating HPLC method with UV detector to the analysis of rivaroxaban in bulk and tablet dosage form. Chem Sci Trans 2014;3:1546-54

29. Reddy MN, Sekhar KB, Kavitha A, Goud ES. Development and validation of a reverse-phase liquid chromatographic method for related substances of prasugrel for 5 and 10mg tablets. Int J Pharm Pharm Sci 2014;6:90-4

30. Nawale R, Pol S, Puranik P, Daud A, Rajkondawar V. Analytical method development and validation of dabigatran etexilate related substance in pharmaceutical dosage form by reverse-phase-high-performance liquid chromatography. Asian J Pharm Clin Res 2018;11:357-64

31. Bhavani G, Hussain SS, Ranjith CH, Kumar AA. Dissolution method development and validation of dabigatran etexilate mesylate capsules by RP-HPLC. Am J Pharm Tech Res 2016;6:200-15.

32. Balaji M, Chhabda PJ, Srinivasarao V, Rao KM, Ramakrishna K. A new and stability indicating liquid chromatographic method for the determination of dabigatran in bulk drug and pharmaceutical dosage form. Anal Chem Au Indian J 2014;14:264-73.

33. Bernardi RM, Fröehlich PE, Bergold AM. Development and validation of a stability-indicating liquid chromatography method for the determination of dabigatran etexilate in capsules. J AOAC Int 2013;96:37-41.

34. Patel BA, Alvi S, Parmar SJ. Development and validation of stability indicating HPTLC method for simultaneous estimation of prasugrel and aspirin. EJBPS 2015;2:718-29.

35. Avachat AM, Yamgar MB. RP-HPLC method development and validation for the estimation of rivaroxaban in bulk and tablet dosage form. World J Pharm Pharm Sci 2017;6:1775-84.

36. Liu C, Yu Z, Wang F, Zhong X, Jiang L, Zhang F, et al. Isolation and structural elucidation of an unknown impurity in prasugrel by semipreparative liquid chromatography. J Chromatogr Sci 2015;53:1163-8.

37. Reddy BR, Rao NV. A stability indicating RP-HPLC method for estimation of dabigatran in pure and pharmaceutical dosage forms. SPJPBS 2014;2:80-92.

38. Ishaq BM, Prakash KV, Mohan GK. Development and validation of HPLC method for determination of prasugrel in bulk and its pharmaceutical formulation. J Chem Pharm Res 2011;3:404-9.

39. Parmar SJ, Patel BA, Jain AP. Development and validation of RPHPLC method for prasugrel. J Chem Pharm Res 2012;4:3373-6.

40. Hadagali MD. Determination of rivaroxaban in pure, pharmaceutical formulations and human plasma samples by RP-HPLC. Int J Adv Pharm Anal 2015;5:65-8

41. Srinivas A, Reddy KS, Sai G. Method development and validation of dabigatran etexilate mesylate by RP-HPLC method and its degradation studies. Int J Trends Pharm Life Sci 2016;2:769-77.

42. Sonia K, Hamunyare N, Manikandan K. Method development and validation of prasugrel tablets by RP HPLC. J Pharm Sci Res 2017:9:1133-8.

43. Walter ME, Perobelli RF, Da Silva FS, Júnior CD, Da Silva IS, Dalmora SL. Development and validation of a stability-indicating RPHPLC method for the determination of rivaroxaban in pharmaceutical 
formulations. Lat Am J Pharm 2015;34:1503-10.

44. Prajapati AM, Patel HA. Simultaneous RP-HPLC method development and validation of clopidogrel and rivaroxaban in synthetic mixture. Int J Pharm 2015;5:610-3.

45. Sriram V, Sriram K, Angirekula J, Tripathi UM, Nayakanti D. Development and validation of reverse phase HPLC method for the determination of impurities in prasugrel hydrochloride. Int J Pharm Tech Res 2012;4:1407-16.

46. Kasad PA. Photolytic-thermal degradation study and method development of rivaroxaban by RP-HPLC. Int J Pharm Tech Res 2013;5:1254-63.

47. Raja MA, Vuyyala L, Banji D, Rao KN, Kumar DS. Development of RP-HPLC method and its validation for estimation of prasugrel hydrochloride. Asian J Res Chem Pharm Sci 2015;3:90-4

48. Rigobello C, Barden AT, Steppe M. LC method for determination of prasugrel and mass spectrometry detection for thermal and alkaline degradation products. Pharmazie 20151;70:515-21.

49. Ahirrao VK, Patil CS, Bembalkar SB, Ubale SB, Marathe RP, Nawale RB, et al. Stability-indicating LC method for the determination of prasugrel hydrochloride in pharmaceutical dosage form. Sci Pharm 2012;80:379-91.

50. Modi VJ, Pingale PL. Development and validation of analytical method for estimation of prasugrel hydrochloride in bulk and in pharmaceutical formulations. Int J Pharm Bio Sci 2012;3:292-8.

51. Kumar SA, Rao JV, Rani KJ, Madhuri SS, Prasad TS. Development and validation of RP-HPLC method for the estimation of prasugrel in bulk as well in pharmaceutical dosages form. Int Res J Pharm 2013;4:254-60.

52. Shivashankar V, Gandhimathi M, Ravi TK. Development of validated RP HPLC method for estimation of rivaroxaban in pharmaceutical formulation. Int J Pharm Anal Res 2015;4:406-10.

53. Latha NM, Supriya P, Ramana GV, Rohith KB, Chaitanya G, Pawar AK. Development and validation of RP HPLC method for the estimation of dabigatran etexilate mesylate (DEM) in bulk form. Int J Pharm Anal Res 2016;5:141-7.

54. Dare M, Jain R, Pandey A. Method validation for stability indicating method of related substance in active pharmaceutical ingredients dabigatran etexilate mesylate by reverse phase chromatography. J Chromatogr Sep Tech 2015;6:1-10.

55. El Zaher AA, El Kady EF, El Houssini OM, El Ghwas HE. Development and validation of stability-indicating rp-lc method for the determination of dabigatran etexilate mesylate in bulk and pharmaceutical formulations. Curr Sci Int 2015;4:402-8.

56. Patel B, Roy S, Ghelani H, Parmar S. Development and validation of RP-HPLC method for estimation of dabigatran etexilate mesylate from capsule dosage form. Int J Pharm Sci Res 2017;8:143-51.

57. Çelebier M, Reçber T, Koçak E, Altınöz S. RP-HPLC method development and validation for estimation of rivaroxaban in pharmaceutical dosage forms. Braz J Pharm Sci 2013;49:359-66.

58. Girase YN, Soni SV. Development and validation of stability indicating RP-HPLC method for rivaroxaban and its impurities. SOJ Biochem 2018;4:1-6.

59. Rajan N, Basha KA. A stability-indicating ultra-performance liquid chromatographic method for estimation of related substances and degradants in rivaroxaban active pharmaceutical ingredient. J Pharm Res 2014;8:1719-25.

60. El-Aziz HA, Ibrahim F, El-Din MS, Fathy ME. Micellar high performance liquid chromatographic determination of a binary mixture of rivaroxaban and clopidogrel and application to biological fluids. Pharm Anal Acta 2016;7:1-11.
61. Meenakshi R, Rao RN. RP-HPLC method development and validation for determination of rivaroxaban in the pure and pharmacuetical dosage form. J Chem Pharm Res 2016;8:38-44.

62. Sahani S, Jain V. A novel reversed-phase high-performance liquid chromatography method for simultaneous estimation of drotaverine hydrochloride, ethamsylate, and tranexamic acid in tablet dosage form. Asian J Pharm Clin Res 2018;11:121-5.

63. Sunny A, Sreedhar C, Rao TS, Akkama HG, Mahapatra A. Development of new analytical method and validation for quantitative estimation of rivaroxaban in formulation and bulk drug. Int J Sci Res Educ 2017;5:6469-78.

64. Prajapati PB, Rakholiya AJ, Bodiwala KB, Marolia BP, Shah SA. Stability indicating HPTLC method for estimation of dabigatran etexilate mesylate in its pharmaceutical dosage form. Eurasian J Anal Chem 2017; 12:75-86.

65. Vaghela D, Patel P. High performance thin layer chromatographic method with densitometry analysis for determination of rivaroxaban from its tablet dosage form Int J Pharm Pharm Sci 2014;6:383-6.

66. Srikanth I, Sharmila P, Vijayabharathi K, Raju M, Naik ML, Nagarjuna K. A validated reverse phase HPLC method for the estimation of prasugrel hydrochloride in pharmaceutical dosage forms. J Indones Tour Policy Sci 2011;2:140-8.

67. Ruzilawati AB, Miran H. Validated high performance liquid chromatography method for analysis of methamphetamine in human urine using liquid-liquid extraction. Asian J Pharm Clin Res 2015;8:199-201.

68. Antovic JP, Skeppholm M, Eintrei J, Boija EE, Söderblom L, Norberg EM, et al. Evaluation of coagulation assays versus LC-MS/MS for determinations of dabigatran concentrations in plasma. Eur J Clin Pharmacol 2013;1:1-7

69. Srikanth I, Rani AP. Development and validation of liquid chromatography coupled with tandem mass spectrometry method for estimation of lenvatinib in human plasma. Asian J Pharm Clin Res 2017;10:120-6.

70. Schmitz EM, Boonen K, Den Heuvel DJ, Van Dongen JL, Schellings MW, Emmen JM, et al. Determination of dabigatran, rivaroxaban and apixaban by ultra-performance liquid chromatography tandem mass spectrometry (UPLC-MS/MS) and coagulation assays for therapy monitoring of novel direct oral anticoagulants. J Thromb Haemost 2014;12:1636-46

71. Zhang WL, Lou D, Zhang DT, Zhang Y, Huang HJ. Determination of rivaroxaban, apixaban and edoxaban in rat plasma by UPLC-MS/MS method. J Thromb Thrombolysis 2016;42:205-11.

72. Reddy GS, Reddy SL, Reddy LS. Development and Validation of HPLC-MS/MS method for rivaroxaban quantitation in human plasma using solid phase extraction procedure. Orient J Chem 2016;32:1145-54.

73. Derogis PB, Sanches LR, de Aranda VF, Colombini MP, Mangueira CL, Katz M, et al. Determination of rivaroxaban in patient's plasma samples by anti-xa chromogenic test associated to high performance liquid chromatography tandem mass spectrometry (HPLC-MS/MS). PLoS One 2017; 12:e0171272.

74. Puram SR, Batheja R, Nithya G. Highly sensitive and rapid evaluation of pyridostigmine impurity $\mathrm{b}$ in human plasma by liquid chromatography coupled with tandem mass spectrometer after administration of pyridostigmine to healthy volunteers in a pharmacokinetic study. Asian J Pharm Clin Res 2018;11:353-7.

75. Yadav S, Dubey N. Development and validation of bioanalytical method for estimation of rivaroxaban using HPLC-PDA in human blood plasma. J Drug Deliv Ther 2017;7:123-5. 